\title{
Common Sense and Scientific Inquiry: Remarks on John Dewey's Philosophy of Educational Progressivism
}

\author{
Anna Malitowska \\ (Adam Mickiewicz University in Poznań, malitowska@amu.edu.pl) \\ Mateusz Bonecki \\ (Adam Mickiewicz University in Poznań, mateusz.bonecki@amu.edu.pl)
}

\section{Introduction}

One of the most important traits of John Dewey's philosophy of new education or his progressive educational ideology is that a learner is defined as an individual capable of acquiring knowledge by means of an autonomously conducted inquiry. Dewey insists that knowledge achieved in the learning process should be embedded in social practices and a student's experiences, and be subject to criticism. This critical dimension requires educational techniques to cultivate and foster - as Dewey puts it in his 1910 work entitled How We Think - "effective habits of discriminating tested beliefs from mere assertions, guesses, and opinions; to develop a lively, sincere, and openminded preference for conclusions that are properly grounded, and to ingrain into the individual's working habits methods of inquiry and reasoning appropriate to the various problems that present themselves" (1910, pp. 2728).

The differentiation between "tested beliefs" and "mere opinions" is apparent in the light of the philosopher's later works in which he focuses on logical, epistemological, and methodological issues. In Logic. Theory of Inquiry (1938) Dewey specifies the nature of scientific inquiry and opposes it to inquiry conducted with a common sense attitude. By stressing Dewey's considerations on the nature of inquiry we shall expose the role of theoretical reflection in the habitual culture in which a learner participates. Finally, we shall ask about the degree to which the reflective reorganization of cognitive structures is interwoven with investigations which theoretically reformulate and redescribe the tissue of common sense beliefs. As we assume, learning appears to be a critical-theoretical process of revising habits based on already gathered experiences.

\section{Common Sense Culture}

In his Theory of Valuation Dewey distinguishes three levels of the formation of desire and interest: biological, psychological, and socio-cultural (1939, pp. 6364). However, as he states elsewhere, "in a cultural environment, physical 
conditions are modified by the complex of customs, traditions, occupations, interests and purposes which envelops them" (Dewey 1938, p. 60). Thus, human agency operates within a culturally constructed milieu. Also, human interests and desires originate from and are shaped by "cultural conditions and valuations" (Dewey 1939, p. 64) which stem from custom, institutions, and tradition.

The most important thing here is that cultural reinterpretation of the physical surrounding "translates" needs, obstacles, and difficulties objectively found within the area of interactions between an organism and its environment into a subject of further conscious cognitive efforts. More precisely, the physical facts experienced by an organism are redefined in cultural terms which enable the individual to become capable of experiencing, defining, and resolving problems. The individual organism now becomes an inquirer; the initial situation of the experience of difficulty can now be improved through cognitive operations oriented at problem solution (1938, p. 60).

The possibility of a transition from difficulties experienced in practical life to a methodical inquiry is guaranteed by a culture which translates biological needs into cultural and social issues invested with linguistic meanings and instituted norms and rules. Thus, to explain this transition, we shall detail two fundamental characteristics of Dewey's understanding of "culture" as (1) a reservoir of linguistic meanings and (2) a normative and regulative factor of human conduct.

Firstly, culture provides a conceptual framework for categorizing and identifying experienced phenomena. As Dewey puts it, the cultural matrix "supplies, through the medium of language, means for explicit formulation of kinds but also extends vastly the variety and number of kinds" (1938, p. 265). Secondly, culture consists of action rules in a broad sense of the term. "Culture institutes and consists of a vast number of ways of dealing with things. Moreover, certain ways of action are formulated as standard and normative rules of action and of judgment on the part of members of the cultural group" (Dewey 1938, p. 265). In analogy to the way in which it suggests the ways for dealing with the environment, culture guides an actor in his interactions with social environment: "persons are sorted out into distinctive kinds on the ground of allowable and prohibited modes of acting toward and with them" (1938, p. 265).

Taking into consideration especially its second role of a normative and regulative factor of human conduct, culture may be defined as "common sense" knowledge since such knowledge

consists in its generalized phase, of a body of such standardized conceptions which are regulative (or are rules) of the actions and beliefs of persons as to what is proper and improper, required, 
permitted and forbidden in respect to the objects of the physical and social environment (Dewey 1938, p. 265).

The valuational essence of common sense penetrates the entire environment, both social and physical, furnishing it with axiological qualifications. As far as actors engage in practical activities in order to satisfy their needs and desires or to achieve their objectives, the world appears to be adequately described in terms prompted by common sense. In consequence, the conceptual framework developed within the common sense of a culture becomes the most "natural", i.e. self-evident and apparent, explication of social understanding of the world.

The concept of "common sense" itself - as a fundamental philosophical category - was introduced and elaborated in the $18^{\text {th }}$ century in the Scottish school of common sense. According to Christopher Hookway, Thomas Reid one of the originators of the school - understood "common sense as a body of ill-defined but self-evident and certain principles which guide our actions and our beliefs, including our philosophical ones" (Hookway 2002, p. 198). The above-mentioned "body of principles" was intended to guide reflection as a criterion of testing the validity of propositions formulated in philosophical theories. Due to the primacy of common sense, if a given philosophical theorem contradicted common sense beliefs, the philosopher was supposed to give it up exactly because of its inconsistency with an opinion widely accepted in a given social setting or even characteristic of entire mankind. Dewey argues, however, that Reid's standpoint merely exposes the aspects of generality, self-evidence, and unquestionability of common sense beliefs while putting aside the issue of the impact of common sense on cultural and liferelated activities. Instead, Dewey (1938) focuses on the "regulative" and "normative" traits of common sense beliefs which make up

a commonplace that every cultural group possesses, a set of meanings which are so deeply embedded in its customs, occupations, traditions and ways of interpreting its physical environment and group-life, that they form the basic categories of the language-system by which details are interpreted (Dewey 1938, p. 62).

Indeed, in the course of everyday practice members of cultural communities guide their conduct by common sense beliefs. In most cases common sense beliefs exhibit self-evidence and confirm their effectiveness. Nevertheless, it does not imply that they are not sensitive to criticism and irrefutable. As we will try to show, the unquestionability of common sense beliefs, as it is presupposed by Reid, is at most a cultural fact, a situation inherited from earlier generations, a result of longstanding practice of a given community. For philosophy of education it means that education ought to provide tools for critical reflection on common sense knowledge. 
According to Hookway (2002, pp. 205-211) the route of critical reconsideration of common sense has been initiated by the originator of classical American pragmatism, Charles S. Peirce, in his conception of "critical common-sensism." Peirce's point is that in the case of inquiry every proposition to which we ascribe certainty should be first put into doubt by means of experience, imagination, and thought experiments. Only withstanding such a critical analysis provides the statement in question with validity which itself never becomes unquestionable and remains open for further inquiry-based criticism.

The issue raised within critical common-sensism also applies to habits which embody the cultural understanding of the world. Dewey is aware of the fact that "the standardized conceptions and rules are for the most part products of habit and tradition" (1938, p. 265). At the same time that is the reason why those "conceptions" of conduct "are so fixed that they are not themselves open to question or criticism" (Dewey 1938, p. 265).

\section{From Common Sense to Scientific Inquiry}

The acquisition of common sense beliefs and the formation of corresponding habits are a part of enculturation and socialization processes. As a result, each culturally educated actor perceives his environment as culturally shaped: the surrounding is understood in terms of cultural linguistic meanings and in the scope of significance it holds in the eyes of a cultural group as a whole. Dewey addresses such a linguistic system as "common" or "ordinary language."

The meanings involved in this common language system determine what individuals of the group may and may not do in relation to physical objects and in relations to one another. They regulate what can be used and enjoyed and how use and enjoyment shall occur (Dewey 1938, p. 115).

The meanings of such a language system organize social experience. They function as a conceptual scheme constituted by interests and occupations; they are maintained within everyday communication and guide both individual and group conduct. According to Dewey, thinking involved in practical operations is a form of concrete thinking. In his words: "when thinking is used as a means to some end, good, or value beyond itself, it is concrete" (Dewey 1910, p. 138). In a more generalized form Dewey's statement could be formulated as follows:

Conception $A$ is concrete if, and only if, the acceptance of conception $A$ leads to an immediate practical operation.

The origin of such an understanding of concreteness of thinking and related concepts may be traced back to Charles S. Peirce and his theory of pragmatic meaning. According to Peirce, semiosis, that is the process of continuous sign transformation, finally leads (or at least is supposed to lead) to a stage when a 
given sign is interpreted by practical actions and practical involvement in the surrounding world. In his popular essay How to Make Our Ideas Clear (1878) Peirce introduced the idea of a "pragmatic maxim" which openly states that comprehensive understanding of signs requires the interpreter or inquirer to grasp the pragmatic meaning, i.e. the meaning defined in terms of practical consequences following from the acceptance of a sign. In his 1903 Harvard Lectures on Pragmatism Peirce points to action-imperatives as a final and pragmatic form to which every meaningful construction of signs should be unfolded. He states that the essence of the entire pragmatism idea consists in the

principle that every theoretical judgment expressible in a sentence in the indicative mood is a confused form of thought whose only meaning, if it has any, lies in its tendency to enforce a corresponding practical maxim expressible as a conditional sentence having its apodosis in the imperative mood (Peirce 1998, pp. 134-135).

Whichever body of theoretical and abstract knowledge we shall analyze, as far as it is considered to be empirical, it is supposed to imply observational which for Peirce always means "practical" - consequences.

Thus, Dewey's "concrete conceptions" employed in concrete thinking processes apply to means, ends, and observable or practically controllable circumstances of human conduct. A vast part of common sense beliefs - since they express the socially shared vision of the surrounding world in which human conduct takes place - can be and usually is expressed only with the use of concrete terms. However, the conceptual framework of concrete thinking affects the nature of reasoning proper to practical inquiries primarily oriented at conduct and procedure rearrangement.
Because common sense problems and inquiries have to do with the interactions into which living creatures enter in connection with environing conditions in order to establish objects of use and enjoyment, the symbols employed are those which have been determined in the habitual culture of a group (Dewey 1938, p. 115).

In his study on inquiry in educational settings Johnston $(2009,46)$ notices that defining problems, in the very first place, in moral terms and categories, in order to create a situation of decision, automatically prevents an actorinquirer from making a due and careful diagnosis of the relations which are constitutive for his situation. In consequence, the knowledge resources for the decision process are - presumably - insufficient. At least, the actor cannot ascertain that he managed to provide the best diagnosis and knowledge possible at the moment. Dewey is convinced that even partial disengagement from practical occupation is a key factor in the improvement of the quality of 
practice: "exclusive preoccupation with matters of use and application so narrows the horizon as in the long run to defeat itself" (Dewey 1910, p. 139).

A conceptual framework determined by practical life requirements is narrow in that it usually precludes identification of new phenomena and new relations between them. An inquirer may experience a magnitude of isolated facts that he is unable to connect. Dewey suggests that a counterweight to this helplessness of common sense is the procedure elaborated within the methodology of modern science. To illustrate the innovative way in which modern science deals with the world, Dewey gives the following example: the conception of water as $\mathrm{H}_{2} \mathrm{O}$ has revealed a multitude of relations of this chemical substance - not only as an object of practical use and enjoyment including hitherto unknown relations with phenomena which have been known for centuries (Dewey 1939, pp. 59-60). However, it would not have been possible at all had modern science not presupposed both a different conceptual framework and a theoretically constituted perspective. It is only thanks to that achievement that an inquirer is able to make innovative inferences, predictions, and to test those predictions empirically.

That is the main reason why Dewey distinguishes between scientific and common sense inquiry. The former is oriented directly at practical problems and behavior adjustments; its goal is the settlement of the problems of action and use. Scientific inquiry, on the other hand, does not produce direct practical instructions and focuses on establishing connections between phenomena, regardless of their instant impact on actual practical issues. Although in both modes of inquiry the product is knowledge, the difference is that common sense knowledge is formulated so that it could provide content for concrete thinking leading to immediate practical conduct. Accordingly, Dewey (1938, p. 60) defines the "world" or "common sense environment" as an environment in which people are directly involved and engaged. Common sense inquiry is from now on understood as an inquiry which aims at "making the required adjustments in behavior."

Only later does Dewey detail his understanding of scientific inquiry in which "there is no direct involvement of human beings in the immediate environment" (1938, p. 61). He states that a scientific procedure is not supposed to "accept what was given and established in common sense" (1938, p. 96). Science is capable of recognizing relations between phenomena which common sense knowledge is not able to grasp; it is "no longer an organization of meanings and modes of action that have their presence in the meanings and syntactical structures of ordinary language" (Dewey 1938, p. 97). Inquiries conducted within common sense and within scientific inquiry differ with respect to their levels of theoreticity. The range of problems to be resolved, put, or transformed on the basis of common sense knowledge and its conceptual framework is limited. It can be extended by the conceptual framework of scientific inquiry and the knowledge formulated on its basis. According to 
Johnston, "scientific inquiry operates largely at the level of abstract reasoning and ideas: common sense operates at the level of the concrete" $(2009$, p. 22). The extension of the scope of scientific inquiry - as Dewey $(1938$, p. 97) argues - is possible because of what he calls a "reflective organization" of common sense which means (i) articulation of hidden implications of common sense beliefs; (ii) an extension of the conceptual framework due to an investigation of issues reaching beyond the area of common sense interest; and (iii) production of an arrangement and order of phenomena with which common sense is unfamiliar.

Usually, practical problems are diagnosed and eventually resolved by means of common sense inquiry. In case of a cognitive failure the thinking process leads to further thinking processes, and so it triggers a rather speculative and theoretical form of inquiry. Regardless of which mode of inquiry is at stake, in each case the process of inquiry gives rise to a body of knowledge formulated in terms of a relevant conceptual framework; the practical world and the scientific image of the world are now subjects of, respectively, common sense knowledge $\left(K_{\mathrm{C}}\right)$ or scientific knowledge $\left(K_{\mathrm{S}}\right)$, as illustrated in Figure 1.

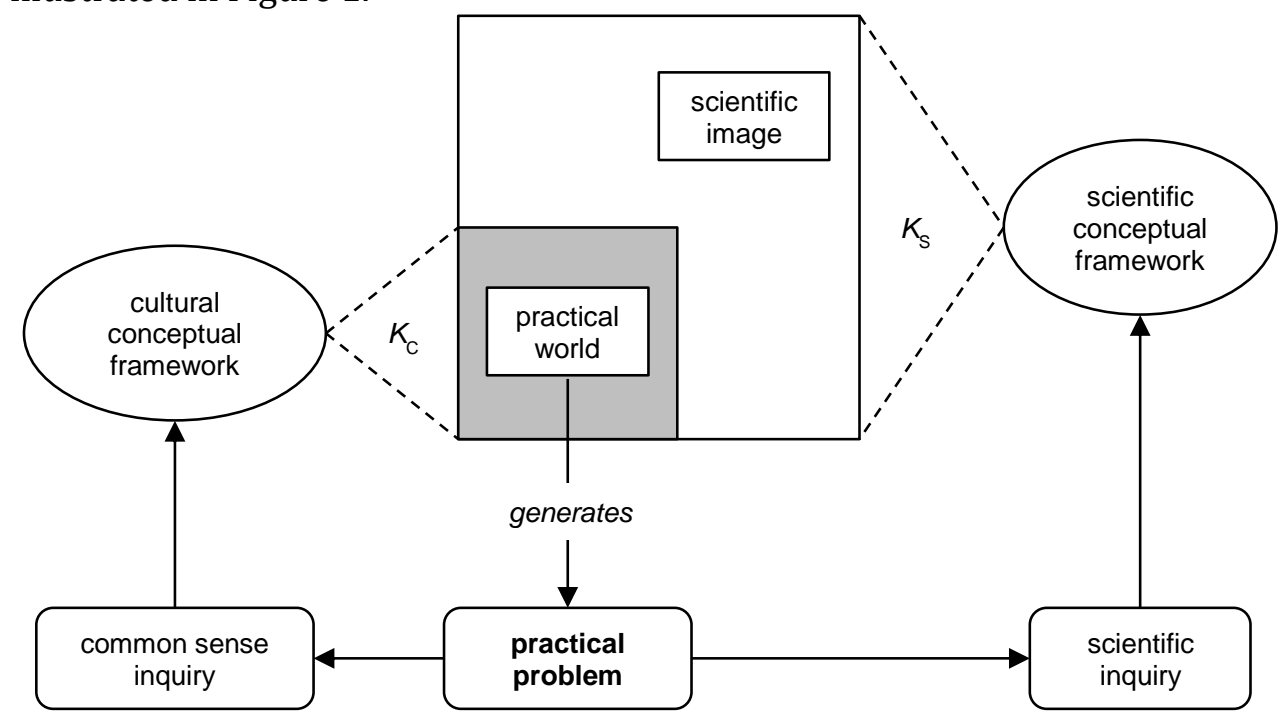

Figure 1: Common sense knowledge $K_{c}$ and scientific knowledge $K_{S}$ as the results of two modes of inquiry conducted within their respective conceptual frameworks

In the scientific approach the practical world (experienced and organized through a conceptual framework characteristic for ordinary language) turns out to be only a part of a larger and more complex scientific image in the sense of a complex relational structure. That structure remains unknown for the practical perspective based on common-sense. Hence, theories constructed in the scientific approach allow for questions, problems, and solutions unattainable 
for common sense inquiry. The scientific image of the world entails regularities and relations impenetrable from the perspective of the common sense body of knowledge $K_{C}$; regularities and laws discoverable within common sense knowledge make but a sub-range of the complex relational structure accessible from within the scientific image. It means that both systems differ with regard to their so-called predictive and explanatory power. This difference could be interpreted as follows:

the predictive and explanatory power of system of knowledge $K_{\mathrm{S}}$ exceeds the predictive and explanatory power of cultural system $K_{\mathrm{C}}$.

In other words, $K_{S}$ provides a more comprehensive understanding of the environing world than $K_{\mathrm{C}}$. When common sense fails to answer certain questions, like Why did this incident happen? or What will happen if such and such circumstances occur? it is more probable that scientific knowledge will settle such questions and indirectly improve human practice by providing it with an innovative theory of reality.

However, the theoretical or reflective organization characteristic of scientific inquiry does not only take place in natural sciences. For instance, Dewey claims that in the field of social sciences and normative disciplines scholars should reconstruct historically given systems of valuations; conclusions drawn from such cultural-anthropological knowledge of past valuations would enable a more extensive prediction of "probable consequences" (1939, p. 58) of human conduct. As it has been discussed elsewhere (Malitowska 2012), in contemporary philosophy of education the pragmatic conception of scientific inquiry has undergone a "philosophical transposition" and, as such, it plays an important role as a pedagogical method facilitating the development of critical thinking.

\section{Informal Education As a Subject to Inquiry}

Dewey's account of "informal education" differs from what contemporary education theorists understand under the term. In Dewey's view the emphasis falls on general processes of socialization and enculturation rather than on detailed activities like learning in the workplace, learning in informal circumstances such as a museum visit, or acquiring knowledge by using media or consuming popular culture. For Dewey, "informal education" becomes synonymous with entering social life.

Social life is a vivid source of educational content: it constitutes a framework within which specialist knowledge and skills gain their social importance, role, and meaning. Informal education takes place as an individual participates in commonly undertaken actions, communicates, and interacts with others. Thus, informal education is understood as a process of socialization and enculturation which provides children and adolescents with 
knowledge, skills, and attitudes that constitute the very core of social life; it is "education which everyone gets from living with others" (Dewey 1916, p. 7). In earlier historical forms of social life all pertinent knowledge was put into practice, so the basic condition of acquiring all relevant knowledge was to participate in social life and, along with others, to practically deal with practical world issues. The so-called real life experience and educational process fell into one.

However, the situation changes as the division of labor and the structure of life become more and more complex, leading to far-reaching specialization and stratification of competences across cultural groups. This is why Dewey calls for constant reflection over the correspondence between the processes of informal and formal education: "There is the standing danger that the material of formal instruction will be merely the subject matter of the schools, isolated from the subject matter of life-experience" (Dewey 1916, p. 10).

Fishman and McCarthy argue that a Deweyan educator has to maintain a continuous balance between the level of a learner's interest in the subject matter and the comprehensibility of the content being learned, between challenges and "being at home", between the senses of unfamiliarity and familiarity. Thus, the efficiency of educational efforts is warranted by a continuous and adequate interplay of educational goals, explicit learning content, and "bridges" linking the student's past and future experiences (Fishman \& McCarthy 1998, p. 37-39).

Since the process of informal education is functional in that it guarantees "continuity", Dewey tries to adopt its basic traits on the ground of formal education. Therefore, the latter has to emulate the social dimension of learning. In order to achieve that goal Dewey starts from the assumption that efficient assimilation of new content by a learner is possible due to its correspondence with the learner's previous experiences. Didactical material should link with possible problem situations the student can encounter and with prior systems of experience. At this point, Dewey (appeals to the psychological principle of apperception which states "that we assimilate new material with what we have digested and retained from prior experiences". In consequence, when considered in school settings, "the 'apperceptive basis' of material furnished by teacher and text-book should be found, as far as possible, in what the learner has derived from more direct forms of his own experience" (1910, p. 199). The correspondence with the "apperceptive basis" both facilitates the learning and introduces elements of social experience (present in previous experiences of the student) into the content of formal education.

Secondly, Dewey explains the role that acquired knowledge and competences play in social life. To set apart from purely "bookish" knowledge, Dewey draws the distinction between information and wisdom. 
Information is knowledge which is merely acquired and stored up; wisdom is knowledge operating in the direction of powers to the better living of life. Information, merely as information, implies no special training of intellectual capacity; wisdom is the finest fruit of that training (Dewey 1910, p. 51).

Thus, wisdom, understood as actionable information, presupposes that a student knows when, how, and for what purpose a given portion of knowledge and competences, may be applied; moreover, a wise learner is also expected to ask about the value-character of both the ends and the means which underlie conduct. The interplay between informal and formal education strives to "avoid a split between what men consciously know because they are aware of having learned it by a specific job of learning, and what they unconsciously know because they have absorbed it in the formation of their characters by intercourse with others" (1916, pp. 10-11).

When considered within institutional schooling practices, "informal education" reproduces certain aspects of social practice in which formally taught knowledge and skills are to be ultimately immersed. Informal education is supposed to furnish acquired competence with social meaning and relevance. Education, as it provides a student with knowledge as actionable information, prepares him to cooperate and communicate with others and to contribute to the social practice and cultural community in which the individual participates.

The teacher assumes a portion of knowledge to be assimilated by students pre-reflectively: they gain competence although they are not aware of that fact; all they acquire is knowing-how rather than knowing-that (Ryle 1949). For instance, when a group in a classroom respectfully and peacefully discusses an exemplary moral dilemma, the mutual respect and inclusive character of the discussion themselves do not become an explicit topic of the lesson. Although they are not thematized at this particular moment, the student gets acquainted with them as presupposed and crucial conditions of every democratic discussion. The educational process realized within such a discussion practice forms the necessary habits significant from the perspective of modern democratic societies. However, as education touches on more complex issues, students get acquainted with more abstract topics like democracy, human dignity, or discourse ethics principles; and it means that informally acquired habits become issues of explicit, formal education.

Still, the informal aspect of education enables a teacher or an instructor to use exactly the same methods and techniques which warrant the effectiveness of socialization processes: direct communication, face-to-face relations, social intercourses, or learning by example or through imitation. When employed in the classroom, they all create situations in which a student spontaneously acquires socially desirable attitudes and habits. From a student's perspective, the social and informal context does not become 
problematic as he acquires new skills and knowledge. The learner is placed in conditions enforced, so to speak, by the teacher who bears in mind their social importance. Common sense rules and beliefs are reproduced in the body of the learner's habits. Hence, the informal education incorporated in the classroom activities:

i. assumes that the subject matter implicit in education is not problematic (i.e. the informally taught subject matter is not put into doubt and critically reconsidered by the learner himself);

ii. is realizable only by means of practice, imitation, socialization, personal contact, examples;

iii. forms habits and transmits common-sensual beliefs constitutive for the social status quo;

iv. contains no theoretical content which could (eventually) function as a referential framework for further evaluation of common-sensual knowledge resources inherited from a culture;

v. elucidates social significance of knowledge and competences as it introduces the role of tasks and processes realized with given (formally transferred) competences in the totality of social life and institutions;

vi. enables the learner, as it is complementary to formal education, to bridge the gap between actual social experience and the material to be mastered by means of formal education.

At this point the question arises whether such a construction of educational environment for the sake of informal education does not simply reduce the teaching process to a transmission of knowledge which strays from the progressive ideal of open-mindedness and problem-solving procedures. Kohlberg and Mayer (1972, p. 460) state that Dewey was far from identifying the fundamental goal of education with a mere transfer of beliefs and attitudes expected and required by the current status quo of the society, as was the case in the educational ideology of Burrhus F. Skinner and his followers within the behavioristic psychology. Dewey, indeed, goes beyond the above-mentioned program of "cultural transmission" because of two fundamental reasons.

Firstly, the learning prepares students to solve problems the society could be, at least at the moment, unaware of, and for occupations that have not even been discovered yet. Education is perceived here within the constructivist approach as a process of development of cognitive structures consisting of beliefs and conceptual frameworks which enable an individual to adapt to or to modify environing conditions. And, since those conditions are reinterpreted in cultural terms, the main task of education is the development of cognitive competence for both common sense and scientific inquiry. According to the study of Kohlberg and Mayer, Dewey represents the position of progressive educational ideology which "equates knowledge with neither inner experience nor outer 
sense-reality, but with an equilibrated or resolved relationship between an inquiring human actor and a problematic situation" (1972, p. 460).

Secondly, education is considered to be a long-run developmental process in which the initially informal content of education is constantly thematized and explicitly placed within the scope of formal and intentional education. The background of social life and experience (i.e. common sense beliefs) becomes the explicit subject matter of a lesson and, as such, is also subject to inquiry. As students proceed to more complex issues elaborated in abstract terms, inquiry stops relying on common sense resources and evolves into a more scientific procedure of an experimental method. In other words, as the learner proceeds with the reflective reorganization of common sense knowledge, he critically and theoretically analyzes the previous content of informal education. It means that the learner improves and reorganizes social practices and experiences, and reflectively revises inherited common sense knowledge (Figure 2).

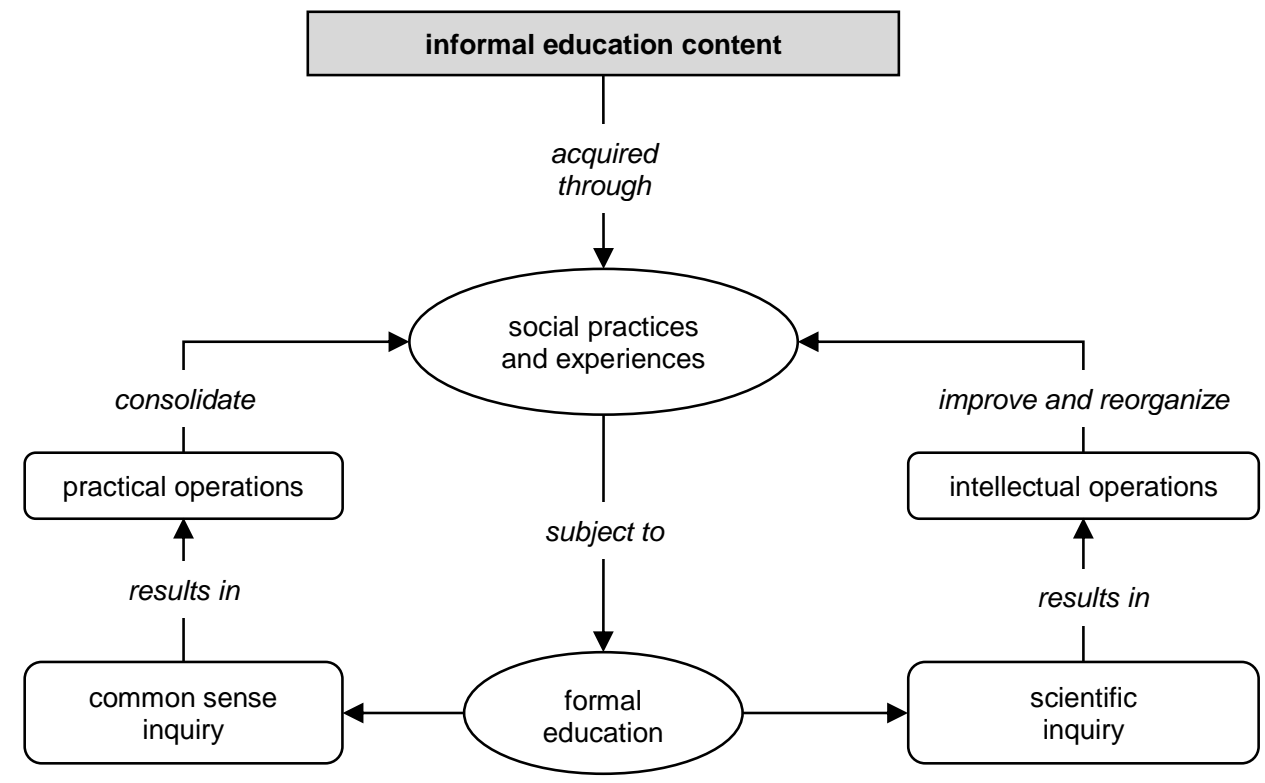

Figure 2: Informal education content as a subject of inquiry.

Issues which have been already practically mastered by students come under theoretical reflection. Theory allows the learner-inquirer to discover relations inaccessible and impenetrable for practical reasoning founded on common sense. Therefore, further education may be considered as a critical reconsideration of previously gathered experiences in the light of newly acquired knowledge. Thus, for Dewey the method of experimentation accompanied by theoretical reflection of scientific inquiry paves the way for "the change of attitude from conservative reliance upon the past, upon routine 
and custom, to faith in progress through the intelligent regulation of existing conditions" (Dewey 1910, p. 154).

Richard Rorty (1982) once gave the opinion that early stages of education realize the aim of socialization and only later, as the student proceeds on the learning path and experiences more and more complex social and natural phenomena, the education changes its course and focuses on the development of a critical attitude toward reality. In fact, he referred to Dewey who holds that the fundamental task of the philosophy of education is to guarantee a balance between informal and formal education, between socialization background and explicit knowledge transfer which leads to a subsequent critical approach to inherited culture and its pertinent commonsensual knowledge resources.

\section{Conclusion}

The above considerations follow Dewey's view that informal education is a product of social practices and intercourses. Interpreted in terms of socialization, informal education is a form of consolidation of what the community knows and is able to do on the basis of shared common sense beliefs. The latter appear to be the ultimate, most elementary, and usually selfevident guidance into the world of social and cultural life. But it is exactly those usually self-evident and well-established rules that veil alternative modes of conduct and problem resolutions.

This is why education is supposed to keep the balance between formal and informal transfer of knowledge, skills, and attitudes, and to employ such procedures of inquiry as proceed from concrete practical occupations, through the cognitive operations of generalization and abstraction, to speculation and theorizing. Only by doing so the habitual culture of a group could be subjected to critical scientific inquiry. It allows for a better understanding of habitual practices of a community and, presumably, opens up an opportunity to put them into doubt, approach them critically, and ask questions whether and how the common sense beliefs could be improved. As Dewey once stated: "Interest in knowledge for the sake of knowledge, in thinking for the sake of the free play of thought, is necessary then to the emancipation of practical life to make it rich and progressive" (1910, p. 139).

\section{References}

Dewey, J. 1910. How We Think. Boston - New York - Chicago, D.C.: Heath \& Company.

Dewey, J. 1916. Democracy and Education. New York: The Macmillan Company. Dewey, J. 1938. Logic. The Theory of Inquiry. New York: Henry Colt \& Company. Dewey, J. 1939. "Theory of Valuation.” International Encyclopedia of Unified Science, Vol. II, No. 4. Chicago: University of Chicago Press. 
Fishman, S. M. \& L. P. McCarthy. 1998. John Dewey and the Challenge of Classroom Practice. New York-London: Teachers College Press.

Hookway, Ch. 2002. Truth, Rationality, and Pragmatism. Oxford: Clarendon Press.

Johnston, J. S. 2009. Deweyan Inquiry. From Education Theory to Practice. New York: State University of New York Press.

Kohlberg, L. \& R. Mayer. 1972. "Development As the Aim of Education." Harvard Educational Review, Vol. 42(4): 449-496.

Malitowska, A. 2012. "How Philosophical Dialog with Children Improves the Moral Judgment and Discourse Competencies." In E. Nowak, D. E. Schrader, \& B. Zizek (eds.) Educating Competencies for Democracy (pp185-202). Bern - Bruxelles - New York - Berlin - Frankfurt am Main Warsaw.

Peirce, Ch. S. 1878. "How to Make Our Ideas Clear." Popular Science Monthly, Vol. 12: 286-302.

Peirce, Ch. S. 1998. "The Harvard Lectures on Pragmatism." In The Essential Peirce. Selected Philosophical Writings, Vol. 2 (pp. 143-257). Bloomington: Indiana University Press.

Rorty, R. 1982. Consequences of Pragmatism. Minneapolis: University of Minnesota Press.

Ryle, G. 1949. The Concept of Mind. Chicago: University of Chicago Press. 


\title{
Anna Malitowska \\ (Adam Mickiewicz University in Poznań malitowska@amu.edu.pl ) \\ Mateusz Bonecki \\ (Adam Mickiewicz University in Poznan, mateusz.bonecki@amu.edu.pl ) \\ Common Sense and Scientific Inquiry: Remarks on John Dewey's Philosophy of Educational Progressivism
}

\begin{abstract}
This paper focuses on analysis of relation between pedagogical and epistemological ideas of John Dewey. Our considerations are divided into four sections. (1) We reconstruct Dewey's conception of culture as a body of normative and regulative common sense beliefs determining human conduct and language use. (2) Further, we compare common sense based inquiry and its scientific mode with regard to their respective conceptual frameworks in order to show that "theoretical-scientific" perspective provides more comprehensive insight into the relations constituting problem situations. (3) We identify informal education with socialization processes and argue that educational process relies on constant reflection on cultural habits. (4) We conclude that competences of using theoretical conceptual frameworks and conducting scientific inquiry play crucial role in Dewey's educational ideology of progressivism since they provide basic tools for critical reconsideration and revision of common sense beliefs.
\end{abstract}

Keywords: common sense, scientific inquiry, critical thinking, theoretical thinking, progressivism, Dewey, pragmatism, informal education, conceptual framework

Ethics in Progress (ISSN 2084-9257). Vol. 7 (2016). No. 1, Art. \#13, pp. 184-198.

doi: 10.14746/eip.2016.1.11 